\title{
THE WOMAN WHO FELL FROM THE SKY
}

\section{Patricia J. Williams*}

Let me begin by thanking Shanthi Senthe, Sujith Xavier, Dean Sossin, Professor Buchananan and Sonia Lawrence, and the dedicated team of students who put this conference together. I felt privileged to have been invited to this very rich colloquy. What a feat of coordination, what a thoughtful collage of ideas.

It was a delight to have been in conversation with you during the hours and days of this conference, to have listened to the grit and specifics of what influenced you, and, presumptuously enough, to have imagined myself alongside you in your heads and your lives, as you narrated them. Your papers have played themselves out in my mind's eye ever since: these so-remarkable, so-vivid stories, so immediate and relatable and courageous, so urgent and spellbinding. The interdisciplinarity of your conversation was also impressive - and such an asset in picking apart the oppressive, shape-shifting dynamics of race. That care in framing issues is essential when it comes to a topic so usually overheated yet so unusually politically consequential. Your papers have inspired me and invigorate all of critical theory. You are doing hard work, community work, multi-generational work, and work-work. What strikes me most is a shared ethic of deep respect rooted in neither exclusivity nor condescension. It is something quite like I remember reading in Kristin Ross's introduction to Jacques Ranciere's The Ignorant Schoolmaster: Five Lessons in Intellectual Emancipation, [p. xix]: "But what if equality... were to provide the point of departure? What would it mean to make equality a presupposition rather than a goal, a practice rather than a reward situated firmly in some distant future so as to all the better explain its present infeasibility?" Ross continues: "Storytelling then, in and of itself, or recounting ...emerges as one of the concrete acts or practices that verifies equality. (Equality...' is neither given nor claimed, it is practiced, it is verified.') The very act of storytelling, an act that presumes in its interlocutor an equality of intelligence rather than an inequality of knowledge, posits equality, just as the act of explication posits inequality."

The papers gathered here are distinguished by just such stories and storytelling. In that spirit, let me contribute a story about stories. It's an odd sad tale under the circumstances, but it refers to an event that was in the news in New York shortly after the conference, affecting the community in which I live, in quite intimate ways, and so it has stayed simmering in the back of my mind, a multi-layered passion play about how race is an overly capacious proxy for narratives of intellect and gender and economics and health and geography, free will, fear of failure, and ultimately the very will to keep on going.

Here is what happened: a woman committed suicide by leaping out a window with her 10 month old baby strapped to her chest in one of those little Snuggly carriers.

I first read about it in the New York Post: The headline read: "Baby Survives Harlem Mother's Death Leap." (Honestly, one can always rely on the NY Post for tabloid concision.) There's so much packed into those few words. Just the word "Harlem" instantly shapes the assumptions about what occurred: she must have been black, desperately poor, a bad mother, probably on drugs. Nuff said, end of story, and you can imagine the effusive stream of online commentary to exactly that effect.

The next day, however, The New York Daily News, coming a little late to the story, ran the report on

Columbia Law School 
its website under the headline "Manhattan mother jumps eight stories to her death with her infant son strapped to her chest; baby survives with minor injuries." With "Manhattan" as the modifier, the online commentary described a different world: this mother was more likely to be seen as white, selfish, desperately ambitious and not on enough drugs for what was assumed to be postpartum depression.

Now as more of the details came out, it was revealed that this mother was also an employee of the Manhattan State Supreme Court and a graduate of Columbia Law School. Of course, there was a stereotyped narrative for that as well: Glenn Beck's news site, The Blaze, reported the story as "Lawyer Mother Leaps From 8-Story Building." Commentary from readers was peppered with surmise about whether the woman was a "femi-nazi" with a liberal death wish, and (with relief that there was one less lawyer in the world.)

And finally, days later, there was this headline, which straddled the question of identity with intriguing ambiguity: "Sources say Harlem lawyer Cynthia Wachenheim penned a 13-page, handwritten suicide note before jumping out of an eighth-story window, taking her son, Keston, with her. The baby was saved from the impact when the woman landed on her back on the pavement." Commentators were confused. Harlem...lawyer? Last name Wachenheim? Son with non-immigrant yet still-funny-sounding name like Keston? Nothing fit with the jigsaw puzzle pieces of stereotypes readily at hand. The armchair pundits were quite enraged.

Anyway, I saved all the headlines I could find about this incident. I took eight of them and turned them into a power point that I shared in a seminar a few weeks later. Afterwards, one woman, a really very thoughtful woman, remarked that she was just blown away by the terrible mystery as to why "all these women" were jumping off buildings with babies strapped to their chests. To say nothing of the fact that "all the babies" survived, every single time. It seemed funny when she said it-I thought I'd been clear about this being multiple accounts of a single incident rather than multiple accounts of multiple incidents---but it has weighed on me over time. Again, this woman is one of the most thoughtful people I know. Her response was a testament to the unconsciously segregating power of indicatives that are not overtly racial or ethnic or gendered. It is a power that inflects all of our perceptions - no one is immune - and that invisibly channels us toward one end or another in our encounters with others.

I remain intrigued by the kind of progression that those headlines reproduce: eight levels of degradation, eight stories of dying, this mother falling through eight headlined categories of being, descending through multiple ontological layers, to her inescapable doom.

Cynthia Wachenheim, accomplished lawyer and Columbia graduate, Harlemite and Manhattanite, depressed wife and bad mother, became a floating signifier in death, more than one being in the terms of our culture, torn into pieces by powerfully loaded descriptors in the mouths of others.

The stories gathered in this journal are a kind of balm to the pain of that phenomenon - and to that incident to which I so-so-so wish I could write another ending. Perhaps it's a bad analogy. But this is not an easy time. And the scholarship modeled here is something vibrant and inspiring: embodying not singular but many modes and moods and languages and skill sets, showing ways to expand and contract in the face of dismembering social forces.

Again, thank you for crafting a body of scholarship that will, for the next generation, provide conceptual landing gear, some grounding in hope, and a vivid sense of our overlapping humanity. You are stewarding into being a safety net of theory, politics, and law that might one day sustain all our 
babies, all our family, all who follow--that they might bounce back from the body blows of a vexed world, unbroken, and carry on. 